\title{
LOS HOSPITALES DE LA SANTA CREU DE BARCELONA Y NUESTRA SEÑORA DE GRACIA DE ZARAGOZA, DOS MODELOS ASISTENCIALES PARA EL HOSPITAL GENERAL DE VALENCIA
}

\author{
THE HOSPITALS OF THE HOLLY CROSS OF BARCELONA \\ AND OUR LADY OF GRACE OF ZARAGOZA, TWO ASSISTANCE MODELS \\ FOR THE GENERAL HOSPITAL OF VALENCIA
}

\author{
Mercedes Gallent Marco \\ Universitat de València
}

Resumen: El objetivo de este trabajo es, por una parte, poner de relieve las gestiones que el consell de la ciudad de Valencia realizó para conocer las ordenanzas y régimen de los hospitales de la Santa Creu de Barcelona y Nuestra Señora de Gracia de Zaragoza a fin de tomarlas como modelos de referencia de las constituciones del Hospital General de dicha ciudad y, en segundo término, mostrar cual fue la documentación que se envió como respuesta a la solicitud formulada.

Palabras clave: ordenanzas, constituciones, Hospital General de Valencia, Hospital de la Santa Creu de Barcelona, Hospital de Nuestra Señora de Gracia de Zaragoza.

\begin{abstract}
The aim of the study is to shed light upon the regulations taken by the Valencia City Council concerning the ordinances and regimes of the hospitals of the Holly Cross of Barcelona and of the Our Lady of Grace of Zaragoza. These were taken as reference models for the foundings of the General Hospital of Valencia. The paper will, additionally, comment upon the respond to the requested petition.
\end{abstract}

Keywords: ordinances, regimes, hospital of the Holly Cross of Barcelona, hospital of Our Lady of Grace of Zaragoza, General Hospital of Valencia. 
Los estudios más recientes sobre la historia de los hospitales abogan por nuevas líneas de investigación desde un planteamiento interdisciplinar que hace posible y abre nuevas perspectivas de análisis: gestión, finanzas, incardinación en el mundo urbano, etc., cuestiones relevantes, sin duda, que evidencian la importancia que las instituciones asistenciales tienen en el contexto de la sociedad y, por ende, de la Historia Social (Henderson 2006; Henderson, Horden y Pastore, eds. 2007; Huguet-Termes y otros, eds. 2014). Teniendo muy presente lo anterior, parece lógico que se deba tener también muy en cuenta el capítulo de las fuentes. ${ }^{1}$ Su búsqueda, partiendo del más mínimo indicio, nunca puede darse por concluida, pues siempre estamos sujetos a que aparezcan otras que aporten nueva información que nos haga replantear lo dicho hasta el momento. En esta línea debe contemplarse este trabajo puesto que pretende dar a conocer una documentación que permite contemplar cómo, en el contexto de la creación de los hospitales generales, ${ }^{2}$ se mantuvieron contactos desde el poder municipal, en este caso, encaminados a buscar modelos asistenciales vigentes en otras ciudades que sirviesen de base para la confección de los estatutos de nuevos centros como el Hospital General de Valencia.

El 24 de abril de 1482 el consell valenciano aprobó una moción presentada por un grupo de jurados en la que, por primera vez, se planteaba formalmente la necesidad que tenía la ciudad de contar con un hospital general. Para justificar la propuesta, sus defensores aducían que en la ciudad siempre se había procurado ejercer las obras de misericordia y la hospitalidad. No obstante, quizás fueran las razones fundamentalmente económicas las que sustentaban tal propuesta, ya que la creación de un hospital general significaba unificar económica y administrativamente los pequeños centros, fundados a lo largo de los siglos XIII y XIV, que dependían del municipio (En Clapers, Beguins, la Reina y Sant Llàtzer) y estaban sujetos a las vicisitudes, sobre todo económicas, que padecía la ciudad, con un hospital autónomo (el de Ignoscents, 1409), que contaba con una economía más saneada, debido fundamentalmen-

1 Archivo de la Diputación Provincial de Valencia (ADPV), Archivo Municipal de Valencia (AMV), Archivo del Reino de Valencia (ARV).

2 Como resalta Conejo (2014: 426): «La gestación -de los hospitales generales- era el punto final de una larga negociación durante la cual se había hecho frente a la lucha de intereses entre el poder civil y religioso, a la dificultad de obtener recursos y a la negativa de los administradores de los viejos asilos a participar de estas fusiones por el miedo a perder los privilegios adquiridos». 
te a la identidad de sus fundadores y a la protección que le dispensaba la monarquía. Así mismo, insistían también en la conveniencia de que el futuro hospital contase con todo tipo de prerrogativas y privilegios tanto reales como eclesiásticos, y se instaba a recabar información sobre los capítulos y ordenanzas por los que se regían los hospitales generales de otras ciudades, pues consideraban que serían útiles para elaborar la normativa por la que debía gobernarse el nuevo hospital general:

E feta proposició per los dits magnífichs jurats, moguts per algunes bones e sanctes consideracions que segons aquesta insigne ciutat és inclinada naturalment en exercici d'obres sanctes e pies, e senyaladament en obres de hospitalidat, ... que sia fet, construhit, edificat e ordenat en la present ciutat hun devot e solempne spital general lo qual sia e puixa ésser dotat e insiguit de totes les gràcies, indulgències, privilegis e prerrogatives que de nostre sant pare, e de la magestat de nostre rey e senyor se puixen obtenir, habent primerament exemples e trellats de regles, capítols e ordinacions de altres spitals generals, per forma que ymittant e inseguint les ordinaciones de aquells e ajustant-hi més avant lo que porrà ésser bo e útil al govern e regiment del dit spital.

A tal efecto, pues, se nombró una comisión que debería estudiar el citado proyecto y presentar sus conclusiones al consell. Este primer intento de unificación hospitalaria no llegó a materializarse debido a que por una parte, causas de carácter político, económico y demográfico impidieron la ejecución del proyecto y, además, no se pudo alcanzar un acuerdo con los diputados del hospital de Ignoscents, que se mostraban muy reticentes hacia el mismo, dado que suponía una merma de su autonomía. El costo del mantenimiento de los hospitales que dependían del municipio debió llegar a ser muy preocupante a tenor de la carta que los jurados dirigieron al papa Alejandro VI el 8 de junio de 1497. En dicha misiva le notificaban el envío de un memorialen el que exponían las penurias económicas y las carencias por los que pasaban los hospitales de la ciudad: «Hi per ço, occorrent-nos huy una gran necessitat per als spitals nostres, los quals sostenen molta pobretat e fretura»y solicitaban su ayuda. Ante esta situación, y posiblemente como forma de economizar la gestión, el consell decidió que a partir del 6 de noviembre de ese mismo año, se unificara la administración de los dos hospitales más importantes de la ciudad: En Clapers y Santa Llúcia o «de la Reina».

En definitiva, la necesidad de la unión hospitalaria era evidente y unos años más tarde el tema volvió a plantearse de nuevo. De hecho, el 7 de junio de 1511, fue aprobada por el consell otra propuesta que, en esta ocasión, sí 
prosperó. Entre los motivos que la propiciaron, cabe pensar, en primer lugar, en un cierto repunte de la economía municipal; en segundo lugar, y dada la ineludible necesidad que tenía el municipio de un hospital general, en que no se escatimaron medios para solucionar cualquier obstáculo o problema que pudiera presentarse; por último, en que se logró alcanzar un acuerdo con el hospital de Ignoscents, que en estos momentos parecía más proclive a la negociación. Finalmente, el 23 de marzo de 1512, se aprobó la moción definitiva en la que se planteaba formalmente la creación de un hospital general en la ciudad de Valencia. Tal como se desprende del acta del consell, los jurados acordaron nombrar una comisión,que estaba compuesta por representantes de las partes interesadas en el proceso: ciudad, cabildo catedralicio y diputados del hospital de Ignoscents, además a un representante de la cofradía de Nuestra Señora de los Inocentes, Mártires y Desamparados, a la que se le encargó la redacción de los capítulos u ordernanzas por las que debía regirse elfuturo centro y arbitrar y solucionar los problemas que quedaran pendientes o que pudieran surgir entre el hospital de Ignoscents y la ciudad. El laudo lo dictó la comisión el 17 de abril de 1512 y el 30 de octubre del mismo año las constituciones del Hospital General de Valencia fueron confirmadas por el rey Fernando II. ${ }^{3}$

La fundación de un hospital general significaba, en definitiva, una racionalización de la economía y de la gestión y evidenciaba, así mismo, un cambio de mentalidad respecto a la cuestión asistencial que estaría definida por la laicización, la medicalización y la especialización. Si bien, como se ha apuntado, el proyecto no se materializó de inmediato, entre las fechas que marcan el inicio y final de este proceso de fusión hospitalaria (1482-1512), los jurados valencianos, haciéndose eco de las recomendaciones propuestas en el acta de 1482, recabaron información acerca del funcionamiento de otros hospitales generales fundados con anterioridad, en concreto el de la Santa Creu de Barcelona y el de Nuestra Señora de Gracia de Zaragoza, con el fin de conocer sus ordenanzas, régimen, etc. y poder tomarlas como ejemplo para elaborar las del futuro hospital general.

En primer lugar se interesaron por la organización económica que regía en Barcelona, donde a inicios de siglo, 1401, los pequeños centros hospitalarios dispersos por la ciudad se habían fusionado en el llamado Hospital General de la Santa Creu. El 22 de febrero y el 17 de abril 1483, se enviaron tres cartas dirigidas a micer Jaume Destorrent, al notario Jaume Liminyana y a los con- 
sellers de Barcelona pidiendo que les facilitasen información sobre el funcionamiento y régimen del centro y que les remitieran las «ordinacions de la taula e del spital general» de esa ciudad, puesto que consideran «que aquexa ciutat té les coses molt bé ordenades» (Gallent, en prensa). ${ }^{4}$

Posteriormente, ya en 1512, en el breve espacio de tiempo (abril-octubre) que dista entre el laudo dictado por la comisión encargada de elaborar y redactar los capítulos del Hospital General y su aprobación por el rey, los jurados vuelven a interesarse por los modelos de gestión y normativa de otros centros. En esta ocasión, los días 8 y 22 de junio de ese año enviaron dos misivas de contenido similar. Una estaba dirigida a los jurados de Sueca y la segunda a todos los oficiales del reino solicitando que encargasen a alguna persona para que fuera a acaptar a fin de recoger dinero que se destinaría a las obras del hospital general, como también se hacía en Barcelona y Zaragoza. Además, el día 30 del mismo mes, escribieron otra carta a Bernat d'Assio, síndico de Valencia en Monzón, pidiéndole que les enviase una copia de los privilegios del hospital general de Nuestra Señora de Gracia de Zaragoza, ya que pensaban «sattisfarien per aquest hospital». ${ }^{5}$ Tales demandas conllevan, sin duda, interrogantes diversos como: ¿Se mandaron copias de los estatutos de los hospitales citados al consell valenciano? Y, si es afirmativa: ¿Qué institución o qué persona las envió? ¿A qué organismo se remitieron: al consell, a la comisión encargada de elaborar los estatutos? ¿Se conserva alguna copia de esta documentación? ¿Dónde se archivó?

\section{II.}

Para responder a estas cuestiones, lo lógico era comprobar, en primer lugar, si en las series documentales del Archivo Municipal de Valencia (Lletres Misives, Manuals de Consells...), había alguna noticia que confirmara el envío por parte los hospitales de Barcelona y Zaragoza de la documentación que se les había solicitado; pero, en estas series, no consta, o, al menos no he encontrado, alguna noticia al respecto. Quedaba por explorar otro archivo, el de la Diputación de Valencia. En él, bajo el epíteto «Fondo Hospital General», se custodia toda la documentación referente al hospital de Ignoscents desde su fundación en 1409, y la generada por al Hospital General desde su fundación 
(García y otros, 1990: 113-142). En este archivo, sí que he hallado información al respecto. La razón por la que los documentos remitidos se conserven aquí probablemente obedezca a que, si bien en un principio se enviaron al consell, éste, a su vez, losdebió entregar a la comisión que estaba encargada de redactar los estatutos del Hospital General, y que posteriormente esta documentación se guardase en el archivo del centro, tal como ordena el capítulo dieciocho de las constituciones de 1512: Ítem, és ordenat que los libres de comptes que-s donaran e de totes cartes de censsals e altres coses concernents al dit spital general, estiguen e resten en la casa del dit spital generaI e archiu de aquella (Gallent, 1980, vol. 2: 434; Gallent, en prensa).

Sea como fuere, en una caja que contiene legajos con documentación muy variada (bulas, constituciones del hospital impresas, etc.) hay copias, muy incompletas y hechas por diferentes escribanos, de las ordenanzas hospitalarias que debieron enviar Barcelona y Zaragoza como respuesta a la petición formulada; así mismo, debe resaltarse que no aparece ningún tipo de información orientativa acerca de la fecha en que estos documentos se mandaron y a qué persona u organismo se remitieron. La documentación que se conserva es la siguiente:

\section{Hospital de la Santa Creu de Barcelona ${ }^{6}$}

En la caja citada aparecen los restos de un cuadernillo, sin foliar, quizás cosido posteriormente, con letra de mediados o finales del siglo XV, que contiene información referente a:

1.1. Capítulos y ordenaciones que Martín I otorgó a la cofradía de la Santa Creu.Al cotejarlos con los publicados por Joseph $\mathrm{M}^{\mathrm{a}}$ Roca y Natividad Castejón, se ha observado que la copia está incompleta, pero aparece la datación del documento: Valldaura 27 septiembre de 1405 . $^{7}$ Sobre la razón por la que se enviaron los capítulos de la cofradía de la Santa Creu, conviene tener en cuenta que el 27 de agosto de 1414 el rey Fernando I otorgó el privilegio de fundación a la cofradía de Nuestra Señora de los Inocentes, Mártires y Desamparados de Valencia, asociación cuya historia corre pareja a la del hospital de

6 ADPV, Sig. IV-4.2, caja 1-legajo 1, sin foliar (son dos cuadernillos, cosidos posiblemente a posteriori; los he foliado correlativamente a fin de facilitar la localización de los documentos que contienen: constan en total de 27 folios $\mathrm{r}^{\circ}-\mathrm{v}^{\mathrm{o}}$, el primero de ellos está suelto).

7 Corresponde a los folios $1 \mathrm{r}^{\mathrm{o}}-8 \mathrm{r}^{\mathrm{o}}$ (primer cuadernillo); en la parte superior del folio $1 \mathrm{r}^{\mathrm{o}}$ aparece: $\mathrm{n}^{\circ} 61$ (Roca, 1920: 110-121; Castejón, 2007: 282-290). 
Ignoscents, con el que protagonizó, a lo a lo largo de su historia, múltiples desencuentros. Al respecto, se puede contemplar la hipótesis de que dichos capítulos se mandaran cuando se fundó está cofradía para que los tomara como referente de los suyos. ${ }^{8}$

1.2. Un privilegio otorgado por la reina doña María al hospital «Privilegium reginum in favorem dicti hospitalis», incompleto y sin datar, ${ }^{9}$ en el que concede su protección a los enfermos, a los niños acogidos en el hospital: ...et etiam privilegiis [...] favoribus, prerogativis, libertatibus et inmunitatibus.. in quo pauperes Christi et miserabiles persones et inmaculi infantes et orphani ignocentes et insensati et qui diversas longoribus t infirmitatibus mentis et corporis elaborant ... y al personal que presta allí sus servicios: administrador, procuradores, mayordomos, cirujanos, físicos, etc.

1.3. Una copia de la escritura de fundación del hospital de la Santa Creu: Creació, institució e unió del hospital de senta Creu de la ciutat de Barchino$n a$. El documento está completo y consta la fecha tópica y crónica: Barcelona, martes 1 de febrero de 1401, si bien, al tratarse de una copia, no aparecen las firmas de los notarios, testigos y signos de validación. ${ }^{10}$

1.4. Por último, aparecen copiadas, sin seguir un orden aparente, las siguientes ordenanzas del hospital ${ }^{11}$ relativas a:

- Nombramiento de administradores: Elecció quatuor administratorum dicti hospitalis videlicet ecclesiasticorum et laicorum. El texto está fechado el 5 de mayo de 1401. En él, se alude a las reuniones que el 15 de marzo de ese año mantuvieron el consell de Barcelona y el capítulo catedralicio y a los acuerdos que se tomaron en ellas en las que, como indica Natividad Castejón: «Fou fixat tambè el règim d'administració que havia de garantir el bon funcionament. S'establí que, per un periode de dos anys, hi hauria una administració formada per quatre persones idònies: dos canonges escollits pel bisbe i el Capítol, i dos ciuta-

8 Los capítulos de la cofradía de Nuestra Señora de los Inocentes, Mártires y Desamparados fueron publicados (Rodrigo, 1922: 43 y 553-575; Gallent, en prensa).

9 Corresponde a los folios $8 \mathrm{v}^{\mathrm{o}}-11 \mathrm{v}^{\mathrm{o}}$ (primer cuadernillo). No me ha sido posible cotejar este privilegio con el original o con alguno publicado. Probablemente se trate de uno de los concedidos por la reina María de Castilla, el 15 de diciembre y el 15 de febrero de 1421, a tenor de la información aportada por otros autores (Danon, 1978: 67 y 158; Roca, 1920: 56 y 58).

10 El documento está en el segundo cuadernillo, fols. 12 ro $-18 \mathrm{v}^{\mathrm{o}}$ (Roca, 1914; Castejón, 2007: 15 y 144 152 -la autora publica un traslado; Danon, 1978: 21 y 149-156).

11 Fols. 19r ${ }^{\circ}-27 r^{\circ}$. Se han cotejado con las ordenanzas publicadas (Roca, 1920: V-XLVI del apéndice). 
dans escollists pels consellers de la ciutat» (Castejón, 2007: 23-24). El notario Bonanat Egidii dio fe pública del documento el viernes 13 de mayo del mismo año. En las ordenanzas que publicó J.Ma Roca, hay un capítulo referente a los administradors, pero no recogen este texto. ${ }^{12}$

- Racional e oydor de comptes. El texto coincide totalmente con el publicado por J. M ${ }^{\mathrm{a}}$ Roca (1920: XXXVII-XXXIX) y sólo añade esta anotación al final: Lo escriva de ratio fa aquest ofici segons damunt es mencionat.

- Offici de porter. Coincide también con el de J.M Roca (1920: XL) y añade igualmente otra anotación al final: [...] un bací de acapte a la porta del dit hospital ha salari.

- Offici de scuders (Roca, 1920: XL).

- De la pena que deven haver los domèstichs del dit hospital que dins aquell juren contra Déu e la sua mare. La ordenanza copiada difiere de la publicada por J. $\mathrm{M}^{\mathrm{a}}$ Roca en su última parte: del senyor Rey e si serà [coronat] a la presó del senyor bisbe e siga a mercè de sos oficials. Tambien se añaden dos puntualizaciones sobre las competencias de jurisdicción: si y- ha sanch va a la cort secular encara que sia [coronat] puix no sia prevere, y Lo senyor Rey ab son privilegi dona la correcciò civil dels oficials del dit hospital als administradors e prior (Roca, 1920: XLI).

- De la pena que auran aquells que en lo dit hospital mouran brega o rumor. ${ }^{13}$

- Dels temps que és donat a denunciar monedes, robes e bens a aquells que leshauran reebudes per lo dit hospital e a quí s'an a denunciare liurar. ${ }^{14}$

- Del sagrament que han a prestar los honorables administradors en lo principi de llur regiment (Roca, 1920: XLIII).

- Del sagrament e homenatge que han a fer e prestar los oficials del dit hospital als honorables administradors de aquell (Roca, 1920: XLIV).

- De la punició que haurà aquell oficial que contrafara en alguna de les presents ordinacions (Roca, 1920: XLV).

12 El autor transcribe en el apéndice documental las ordinacions de 1417 y numera las páginas con caracteres romanos (Roca, 1920: V-XLVI y VIII-IX).

13 La copia de esta ordenanza, aunque el contenido es similar, difiere en la redacción de la transcrita por Roca (1920: XLI).

14 Difiere de la transcripción de Roca en alguna palabra (1920: XLII). 
- Retenció de tolre, enadir, mudar e variar e de nou ordenar sobre les dites ordinacions e cascuna d'aquelles (Roca, 1920: XLVI).

- Por último, a continuación esta ordenanza, aparecen dos textos. El primero recoge un acuerdo de los canónigos del cabildo de Barcelona, según el cual, a su muerte, su lecho se entregará al hospital y si sus herederos no quisieran hacerlo debían donar 10 libras. En el segundo, se da cuenta de los preveres que hay en el hospital, siete en total, y las funciones que desempeñan: enfermer, guardaroba, comprador, reboster panicer e boteller, rector y pacioner, que es el encargado de leer la pasión de Cristo a los agonizantes. A esos clérigos hay que añadir otro más, titular de un beneficio que se instituyó en la iglesia del hospital, cuyo cometido es ayudar en el centro y al que se le asigna un salario de 50 sous.

\section{Hospital de Nuestra Señora de Gracia de Zaragoza ${ }^{15}$}

En la misma caja se conserva también un pequeño legajo, sin ninguna nota identificativa (sólo, en el reverso del primer folio pone duplicat en), de lo que deben ser los restos de un cuadernillo. Su lectura hace suponer que se trataba también de parte de la documentación que se envió a los jurados valencianos como respuesta a susolicitud del 30 de junio de 1512.

2.1. En la primera parte hay una copia, incompleta y escrita en latín, de la confirmación que Alfonso V hizo el 5 de mayo de 1425 de las primeras ordenanzas de este hospital. En los signos de validación del documento aparece el nombre del secretario real, Francisci d'Arinyó. Según afirma Cristina Monterde, se tiene referencia de estas ordinaciones primitivas a partir de las menciones que se hacen de las mismas en las promulgadas en 1496 por Fernando el Católico y en las nuevas ordenanzas que encargó redactar a su hijo Alonso de Aragón, arzobispo de Zaragoza, datadas, se supone, hacia 1508 (Monterde, 2008; Baquero, 1952). En este punto cabe plantear la hipótesis de si la copia enviada a Valencia se hizo a partir de las ordenanzas originales de 1425, de las que, según parece, no se conoce ningún texto relativamente coetáneo (Monterde, 2008: 506-507).

2.2. La segunda parte del legajo prosigue con un texto, posiblemente no muy posterior y escrito por diferente mano, en el que se recogendiversos capí-

15 ADPV, Sig. IV-4.2, caja 1-legajo 2, sin foliar. (en total consta de 4 folios $\mathrm{r}^{\circ}-\mathrm{v}^{\circ}$ ). en el reverso del primer folio, que está en blanco pone duplicat en. Cfr. Apéndice documental. 
tulos referentes a la normativa y organización del hospital, el trato que reciben los enfermos, etc. Al cotejar estos capítulos con los de 1496 publicados por C. Monterde, se observa que, si bien no coinciden en la redacción, sí puede apreciarse, sobre todo en la parte dedicada a los enfermos, una cierta similitud y una reelaboración del contenido, debido, quizás, a nuevos planteamientos o necesidades que hayan surgido. Por ejemplo, en la copia conservada en el archivo de la Diputación de Valencia, el texto, cuando se refiere a cómo deben ser recibidos los enfermos en el hospital, dice: es ordenado quel enfermo no pueda ser recebido en la enfermería sino que primero sia confesado y conbregado.... Cuando se refiere a las oraciones y consuelo prestado a los moribundos indica: así mesmo dos clérigos que tienen cargo de leer las pasiones a los que estando in articulo mortis y darles la extremaunción, absolución plenaria e confirmarlos en la fe e decirles otras devociones devotas. Sobre las normas de higiene que se deben guardar con los enfermos que acuden al hospital señala: antes que dentra el dicho enfermo en la enfermería lo squilan e lo limpian por tenerlos limpios en los lechos... Comparando estos textos con lo ordenado en las constituciones de 1496 sobre esos mismos aspectos, se puede apreciar que el contenido de ambos textos es prácticamente el mismo: ...que ningún enfermo pueda puyar a las dichas enfermerías sino primero recebidos los sacramentos. Que los dos presbíteros capellanes tengan cargo en las enfermerías de leer las pasiones a los enfermos que serán afrontados en el artículo de la muerte...; o sobre la higiene: primerament luego que a las enfermerías será puyado si mester será que les faga lavar e limpiar los piese fazerlos poner en el lecho bueno y limpio (Monterde, 2008: 514-517).

\section{III.}

Como punto final de este trabajo, quisiera resaltar dos aspectos. En primer lugar, y tal como ponen de relieve los más recientes estudios sobre el tema de la asistencia hospitalaria, ${ }^{16}$ la necesidad de la creación de hospitales generales se hizo patente en el ámbito europeo y por ende, también, en el espacio de la Corona de Aragón. Además este proceso, en ocasiones largo y costoso, como en el caso de Valencia, quizás permita vislumbrar un tímido cambio de actitud respecto a la cuestión asistencial en lo que se refiere al control de los poderes públicos, presencia de los profesionales de la sanidad en los centros y a la es- 
pecialización. Este último aspecto cada vez se va haciendo más relevante, puesto que se comienza a separar a los enfermos en función de las patologías que presentan; sólo los lazaretos, que albergaban a los enfermos de lepra u otras afecciones dermatológicas, permanecían en su emplazamiento original puesto que se pensaba que la lepra era contagiosa. Tal es lo que ocurrió en el Hospital General de Valencia. Una zona siguió destinada a los niños expósitos, continuando la labor desarrollada en los hospitales de En Clapers y la Reina (Gallent, 1980: 82-83; Jávega, 2010); otra, ubicada en la parte que correspondía al antiguo hospital de Ignoscents, siguió albergando a los enfermos mentales. Además, se crearon tres secciones nuevas, la de fiebres, la del mal de sement (morbo gallico) y la de heridos (López, 2012). Los leprosos, por su parte, continuaron viviendo en su antiguo centro, el hospital de Sant Llàtzer, situado a las afueras de la ciudad, según se estipula en el tercer capítulo de las constituciones del Hospital General:

Ítem, ordenen que los magnífichs jurats, racional e síndich, ab la auctoritat damunt dita ajustaran e uniran la casa e renda de Sanct Làzer ab lo dit spital generaI, però per quant los pobres malalts del mal de Sanct Làzer es mal contagiós, no es bo que stiguen en lo dit spital generaI. Per ço, es concordat que los dits pobres hajen de star e habitar en lo dit spital e casa de Sanct Làzer, e que sien sostengudes e alimentats per lo clavari del spital general, axí com proveyran en lo dit spital general, e açò a coneguda dels quatre administradors del dit spital general (Gallent, 2012: 119).

Es decir, y como en otras ocasiones he puesto de relieve parafraseando a M. Mollat, la unificación hospitalaria evidencia que, una vez entendida la sanidad como un problema social y responsabilizada la administración pública sobre esta cuestión, la unión de los hospitales debe ser contemplada como la búsqueda de una racionalización de la sanidad, esto es, una mejor gestión, una mayor rentabilidad y, sobre todo, una asistencia más eficaz (Mollat, 1982: 7-8).

En segundo término, y más que resaltar un aspecto sería plantear otra perspectiva de investigación, es preciso considerar que, como se ha expuesto en este trabajo, al igual que la ciudad de Valencia buscó las ordenanzas por las que se regían otros hospitales generales para que le sirvieran de modelo al elaborar la normativa de su Hospital General, este hecho también pudo haberse dado en el caso de otros hospitales, lo que, en mi opinión, plantea la oportunidad de una comparación sistemática de los estatutos por los que se regían los hospitales, tanto en el ámbito peninsular como europeo, que permitiría 
conocer con mayor profundidad los cambios ideológicos, modelos de gestión, organización y asistencia, tanto sanitaria como social. ${ }^{17}$

Por esta razón, puede deducirse además, que, si importante es estudiar la historia de los grandes centros asistenciales urbanos, tanto o más importante es el estudio, la localización y reconstrucción y de la red sanitaria de un país, como ha puesto de relieve Joan J. Busqueta (2014): Se trata de llegar a conocer mejor la realidad, en este caso de aquellos centros de hospitalidad vinculada a núcleos pequeños y medianos de población y el papel que desempeñaron más allá de la asistencia a pobres, peregrinos y enfermos: sus mecanismos de gestión, sus relación con las vías de comunicación, su área de influencia. ${ }^{18}$

Lo anterior supondría centrar el interés en la identificación de los pequeños hospitales rurales ubicados en villas y pueblos alejados de la urbe, promovidos por cofradías religiosas o laicas,por particulares, etc., por más dificultad que entrañe el encontrar indicios de los mismos y la búsqueda de fuentes, por lo general incompletas y dispersas. Considero, además, que el conocimiento de la asistencia, ya como nosocomios o como albergues para viajeros y peregrinos, que se ofrecía en esos pequeños centros es un eslabón muy importante para conocer la estructura sanitaria, por supuesto en ciernes, de un país.

17 En este sentido se plantean algunos estudios (Huguet y otros, eds. 2014).

18 Relativo a esta cuestión (Navarro, 2000: 565-568). Así mismo es ineludible citar un magnífico trabajo de fin de master presentado en la Universidad de Zaragoza sobre la red de hospitales en Aragón (Villagrasa, 2014). En el caso del País Valenciano existen trabajos sobre los hospitales de municipios importantes caso de Gandía o Xàtiva, por ejemplo, pero no hay ningún un estudio sistemático de la red hospitalaria del mundo rural durante el Medievo. 


\section{Apéndice Documental}

1512, junio, 8. Valencia

Los jurados valencianos en una carta dirigida al justicia y jurados de Sueca, les piden que al igual que se hace en Zaragoza y Barcelona, encarguen a alguien para que vaya a «acaptar», a fin de recoger limosnas para la obra del Hospital General.

AMV, Lletres Misives, $\mathrm{g}^{3}-38$, fol. 55 r.

Cit. (Gallent, en prensa).

Als molt honorables los justícia e jurats de ${ }^{19}$ loch de Çuequa:

Molt honorables senyors. Ja deveu saber com en la present ciutat de València novament se construeix hun spital general al qual son stats vuyts tots los altres spitals. E per que los beneficis e caritats del dit hespital son e han de ésser grans, segons los principis que de present veem, es cert que les despeses seran e han de ver axí mateix grans y excessives y per ço es mester, per conservació del dit hespital general, que los administradors de aquell ab suma diligència entenguen axí com se fa en Çaragoça e Barchinona, en replegar e haver totes les almoynes que-s poran, axí en lo present regne com en altra part per conservació e augment de tanta hospitalitat, de la qual resulta mèrit e benefici per a tots. E per ço, notificant-vos les dites coses com a feels Christians vos diem e encarregam e exortam de part de Nostre Senyor Déu e nostra, vullau acomanar a alguna bona persona de aquexa vila que en nom e loch del dit hespital general porte un bací ab lo qual entre l'any acapte e participe de vostres caritats ${ }^{20} \mathrm{e}$ aço mateix porà fer e farà de recollir e plegar de les messes que [a cas es poran collir] e d'aquestes coses axí plegades donarà rahó e respondrà al magnífich en Conrat d'Alpont, ciutadà d'aquesta ciutat e clavari del dit hespital general, de forma que Nostre Senyor Déu sia loat e lo augment de cosas tant pia migençant les vostres caritats e altres se conserve e augmente e tinga-us la Sanctissima Trinitat en sa continua guarda, protecció e custòdia.

De València a VIII de juny any MDXII.

Los jurats de València a vostra honor, promptes e ben apparellats

1512, junio, 22. Valencia.

Carta de los jurados a los oficiales del reino en la que les informan de la necesidad de dinero para la construcción del Hospital General. Les piden que encarguen a gente que vaya a «acaptar», como se hace en Zaragoza y Barcelona, con objeto de recoger dinero para la obra.

AMV, Lletres Misives, $\mathrm{g}^{3}$ - 38, fol. 55 v-56 r.

Cit. (Gallent, 2012; Gallent, en prensa).

19 A vila, tachado en el texto.

20 Axí mateix tachado en el texto. 
Als molt magnífichs e honorables e savis senyors universes e sengles officials e altres qualsevol persones dins lo present regne de València e en qualsevol ciutats, viles e lochs de aquell constituits e jurisdicció exercints e lochtinent de senyoria tenint e a qualsevol d'aquelles, al qual $\mathrm{o}$ al quals les presents pervendran e o presentades seràn los jurats de la insigne ciutat de València, saluts ab creximent de prosperitat e honor:

Ja deveu saber com en la present ciutat de València novament se construeix hun hespital general al qual són stats venits tots los altres hespitals de la dita ciutat. E per que los benefficis e caritats del dit hespital general són e han de ésser grans, segons los principis que de present vehem, es cert que les despeses $<$ seran $e^{21}$ han de ésser axí mateix grans y excessives, per ço, es mester per conservació del dit hespital general que los administradors de aquell, ab summa diligència entenguen axí com se fa en Saragoça e en Barchinona, en replegar e haver totes les almoynes que.s poran haver, axí en lo present regne com en altra part per conservació e augment de tanta hospitalitat $/ /^{56 r}$ de la qual resulta mèrit e beneffici per a tots. E per ço notifficamvos les dites coses, com a feels Christians ${ }^{22}$ diem, encarregam e exortam de part de Nostre Senyor Deu e nostra, a vosaltres e a cadahu de vos que en cadahuna ciutat, vila e loch de vostra jurisdicció e destret vullau acomanar a alguna bona persona $<$ ecclesiastica o secular $>^{23}$ per los jurats de tal ciutat o vila o loch elegidora que en nom e loch del dit hespital general porte hun bací ab lo qual entre l'any acapte e participe de vostres caritats e almoynes. ${ }^{24} \mathrm{E}$ de aquestes coses axí plegades donarà rahó e respondrà al magnífich en Conrat d'Alpont, ciutadà d'aquesta ciutat e clavari en lo present any del dit hespital general, de forma que Nostre Senyor Déu sia loat e lo augment de cosa tant pia migençant les vostres caritats e altres se conserve e augmente, certifficant-vos que ultra lo mèrit e premi <de Nostre Senyor Deu $>^{25}$ que axí vosaltres com les persones qui aquest càrrech acceptaran aconseguiren <nosaltres vos he tendrem a singular gràcia e complacencia $>^{26}$ e tingaus la Sanctissima Trinitat en sa continua protecció e guarda.

Dada en València a XXII de juny del any de la Nativitat de Nostre Senyor MDXII.

3.

1512, junio, 30, Valencia.

Los jurados piden a Bernat d'Assio, síndico de Valencia en Monzón que envíe copia de los privilegios del Hospital General de Zaragoza.

AMV, Lletres Misives, $\mathrm{g}^{3}-38$, fol. $58 \mathrm{r}$.

Cit. (Gallent, 2012; Gallent, en prensa).

Al molt honorable e car frare en Bernat d'Assio, síndich de la insigne ciutat de València en Monçó:

21 Seran e, interlineado

22 Vos, tachado en el texto.

23 Ecclesiastica o secular, interlineado.

24 E aço mateix porà fer e farà al recollir e plegar de les messes que acapte vulla eser spe collir, tachado en el texto.

25 De Nostre Senyor Deu, interlineado.

26 Nosaltres vos he tendrem a singular gràcia e complacència, interlineado; agratiment lo dit clavari pagara e... de ço que per les dites persones sera replegat e exhigit pagarà e satisfarà a cascuna d'aquelles de sos treballs, tachado en el texto. 
Molt honorable e car frare, nosaltres scrivim al magnífich vicecanceller sobre los privilegis que seria mester se atorgassen per al Hospital General de la present ciutat ab crehença a vos acomanada, la qual letra va ab la present, pregam-vos li doneu dita letra e entengau ab summa diligència en lo que sabeu que cumple per al augment e conservació del Hospital General. E per que los privilegis del Hospital General de Çaragoça ${ }^{27}$ satisffarien per aquest hospital, es mester que de continent trametau a Saragoça puix stà prop d'aquí e que hajan còpia dels dits privilegis a despeses d'aquesta ciutat e segons aquells treballarem, sien atorgats los privilegis per aquest Hospital General, remetent-ho a la prudència e discreció vostra. Axí mateix vos trametem copia de dos privilegis de la casa de les Repenedides los quals satisffaran per al dit spital general ${ }^{28}<\mathrm{e}$ si més ne haguessen trobat que satisfessen los hagueren tramesos, car nosaltres havem fet cercar los que vos nos haveu scrit del l'espital d'En Clapers e de la Reyna e de Sent Làzer e non havem trobat alguns si no sols los dos de les Repenedides que us tramettem $>$. E tingaus la santa Trinitat en sa guarda.

De València a XXX de juny any MDXII.

Los jurats de València a vostra honor promptes e be apparellats.

4.

S.a. [1496?].

Copia de las constituciones y «ordinaciones» del hospital de Santa María de Gracia de Zaragoza.

ADPV, IV-4.2, caja 1, legajo 2, s.f.

Cit. (Baquero, 1952; Monterde, 2008; Gallent, 2012; Gallent, en prensa).

... proseque et future iudice et iudices impetrare et su pactos recusare emparare et desemparare seu emparari et desemparari facere protestati et requirere protestacionibus et requisicionibusbus respondere et inde [sii...re] facere publicum et publici instrumenta componere et travingere et paci ac etiam stipulari absoluciones, difiniciones et remissiones facere beneficium restitucionis in integrum postulare et obtinere tam prius [...] quam mordentur procuratores et procuratores ante litem et post litem contestatam simul et diversum substituere sustitutos destituere et revocare ac de novo alium et alios substituere tociens [...] vobis videbitur expedire et generaliter omnia alia facere super pre dictis et circa ea que nos ut protector et nomini dicti hospitalis facere possemus si personaliter interessemus seu possemus etiam interesse etiam si maiora fuerunt aut fuit superius expressatis etiam si talia fuerint aut fuit que specialem aut singularem exhigant aut requirant potestatem quoniam nos vobis et substituendo substituendis a vobis in predictis et circa predicta et super universis negociis et iuribus dicti hospitalis eosque dependentibus incidentibus emergentibus et connexis singularem et generalem administracionem cum plenissima facultate omnes vices nostras ponentes vos in locum nostrum dicte nostre regie plenitudine potestatis comendamus per presentem. Et volentes vos dictos procuratores presentes et alium seu alios qui pro tempore fuerint qui vero sint eligendi hoc modo videlicet quod

27 Las ordenanzas del Hospital de la Santa Creu de Barcelona las habían pedido en 1483 cfr. docs. 19, 20, 21 y 22). Así mismo, en el ADPV se conserva parte de una copia de los estatutos del Hospital de Santa María de Gracia de Zaragoza (cfr. doc. n 13).

28 Signo de llamada; anotado en margen izquierdo: $\langle\ldots\rangle$; se inserta en el texto. 
si alter ex vobis deceserit aut morbo detinebitur gravissimo aut erit instante senectutis crepidine constitutus quod ab eo nullum comodum pestoletur hospitale predictum aut per annum absens fuerit a civitate, tali casu residui sorii aut procuratores unánimes loco illius mortui vel absentis vel sinis si mortus ipse vel absens fuerit clericus clericum si civis civem secundum qualitatem et esenciam dicti defunctis eligere teneanturpariter et subrogare per illiumque prestare facere debitum iuramentum sic et prout vos dicti procuratores presentes modo predicto prestare tenemini et astricti estis ac substituendum seu substituendos a vobis dictis procuratoribus presentibus et futuris relevari $a b[\ldots]$ onere satis dandi fide iubendo in hiis quo vobis [pro... que] nostra bona fide regia quo id quod per vos aut per dictos substituendo a vobis actum et factum exciterit quoquomodo sive ges[emin?] in premissis et circa premissa teneri et observari ab omnibus faciemus [gra...] quod vos dicti procuratores et quicumque qui pro tempore fuerunt non possitis de bonis dicti hospitalis pro pensione salario aut remuneracione laborum nostrarum procuracionem seu administracionem quidquam recipere sed quod omnia per vos vel subsciti nos a vobis habita et habenda in usus propios et non alia dicti hospitalis debite commutantur et ut dictum hospitale eiusque redditus, proventus et alia bona predicta sint continue $[\mathrm{si} . . . \mathrm{o}]^{29}$ bono ac fideli regiminem et administracionem ac in eisdem regiminem et administracionem nullius ambiguitatis suspicionis et suspiciones scrupulum possit aliquatenus adhiberi ducimus ordinandum quod nos et archiepiscopus capitulum sedis civitatis huiusmodi ipsaque civitatis coniuncti si voluerimus et voluerunt semel in anno aut alius possimus per nos aut deputatos a nobis et per dictos archiepiscopum capitulum et civitate dictum hospitale visitare illiusque redditus et bona recognoscere et rendere ac administracionem, regimine et exercicium per vos dictos procuratores infra annum actum et factum absque aliquo salario aut remuneracione aut stipendis sumptibus ne dicti hospitalis et bonorum ipsius diminucione investigare et discutere taliter quod si aliquo ex vobis dictis procuratoribus repertus fuerint in premissis delinquens negligens aut remissus queat in premissis ut convent de opportunis remediis provideri ad servicium Dei et commodum utilitatem et augmentum hospitalis predicti reique publice eiusdem visitacione autem altaris et utensilium ipsius soli archiepiscopo vel suo vicario generali reservata.

Mandantes presentem universis et singulis officialibus nostris maioribus et minoribus quacumque fulgeat preheminenciam et dignitate et potissimum auditoribus alguaciriis et iudicibus curie nostre et aliis/s.s. quibusvis ad predicta delegatis aut delegandis eorumque locatenentis presentibus et futuris sub nostre ire et indignaciones incursu quatenus mihi et super peticionibus querelis et demandes per vos aut substituendum seu substituendos a vobis propositis seu proponendis allegatis seu allegandis faciant iusticiam expeditam itaque vocati et vocandis super predictis procedant breviter simpliciter sumarie et de plano ac sive strepitu et figura iudicii sola facti veritate accenta ei sive debito terminetur pro ut de foro iusticia et racione fuerint faciendum maliciis defugiis et excepcionibus omnibus proculpulsis huiusmodi autem procuracionis instrumentum actum revocacionem procuracionem [sunt...] generali vel speciali quoquomodo continentem noluus nec intendius revocari nisi de huiusmodi sit facta de verbo ad verbum mencione specialis in actu aut revocacione predictis in quorum premissorum testimonium presentem fieri iussimus nostro sigillo comuni impendenti munitum. Datum et actum in civitate Cesarauguste die quinta Madii anno a Nativitate Domini Millesimo Quadringentesimo Vicesimo Quinto regnique undécimo.

$29[$ si...] roto en el original. 
Sig+num Alphonsi Dei gracia regis Aragonum, Sicile, Valencie, Maioricarum, Sardinie et Corsice, comitis Barchinone, ducis Athenarum et Neopatrie ac etiam comitis Rosilionis et Ceritanie qui predicta laudamus, concedimus et firmamus ac etiam aprobamus. Rex Alphonsus.

Testes fuerunt ad predicta presentes Belengarius de Bardaxino iusticia et Ioannes de Gurrea baiuliis generalis regni Aragonum, milites consiliarii domini regis predicti.

Sig+num mei Francisci d'Arinyo secretarii domini regis predicti qui de ipsius mandato predictis interfui eaque scribi feci et clausi corrigit autem in lineis XXI «et sive penaque et sive penaque [uncte]» et XXV a «contestatam simul et divisim» ac in línea firme dicte domini regis «aprobamus».

Apres $^{30}$ de la dicha ordinació este spital passava mucho detrimento en las cosas necesarias a utilitat e provecho de los dolientes Innocentes y criaturas que en el dicho hospital se acoxen, fue deliberado por la ciudat que el dicho regimiento fuesse ampliado más de lo que solía según se sigue:

Ítem, fue ordenado per los sennores jurados de la dicha ciudat que fuesse regidor el jurado segundo el qual de contínuo lo es en el dicho regimiento del dicho spital.

Ítem, la dicha ciudat tiene al dicho spital jus protección y salvaguardia e todas sus rendas, deudos e emolumentes assí como bienes de la ciudat propios.

Ítem los caballeros y fidalgos tienen meso otro regidor ensemble con los otros regidores susso dichos.

Ítem, así mesmo los notarios de caxa de la dicha ciudat tienen otro regidor con los dichos ensemble, los quals notarios e capitol tienen tal ordinación que el primero domingo de cadaún mes se llegan y cadanno manifiesta las lexas que en aquel mes han fecho los que son fallecidos al notario que es del dicho spital por quanto cada qual notario reduce en memoria a los testadores, les acuerde de los pobres del dicho spital y el dicho notario asienta de su mano las dichas lexas en el Libro de Lexas de testamentos del dicho spital.

Ítem, los dichos regidores tienen substituydo uno en lugar suyo, clérigo, el qual rige y ministra por los susodichos todas las cosas del dicho spital y dar conto de aquellas a los dichos regidores.

Ítem, las pecunias, rendas, elemosinas e emolumentes del dicho spital hay hun receptor o bolsero, mercader abonado, el quel recibe todas las dichas rendas del dicho spital y las pone en una caxa que está en el archiu del dicho spital, de la qual caxa tiene una llave el dicho receptor y otra el regidor principal, clérigo, que de presente son mossén Capata e don Pedro Torrero y los dichos pagan todos los pagamentos mayores así como son pan, vino, carne y nodricas de criaturas e otras compras que se ofrecen de mercar en el dicho spital.

Ítem, es ordenado por la dicha ciudat quel dicho receptor de cadaun mes, los dineros que son menester por a las cosas necesarias en la casa por menudo, es a saber, por a gallinas, güebos, pansas, fruta, calceros de innocentes, reparos de cozina et otras cosas semeiantes por a necessi-

30 El cuadernillo prosigue con un texto escrito por diferente mano, posiblemente no muy posterior, en el que se recogen fragmentos relativos a la normativa y organización del hospital, trato que reciben los enfermos, etc. 
dat de la casa et el dicho regidor o substituydo de conto a los regidors de lo que él ha despendiado en las dichas cosas necessarias.

Et los dichos regidores dan conto a los contadores elegidos por la ciudat que son dos ciudadanos principales y aquellos en suma fan relación a los sennores jurados y apres fan su difinimiento a los dichos//s.s.

Ítem, es ordenado por la dicha ciudat que los regidores del dicho spital no pueden vender ninguna propiedat del dicho spital sin decreto e consentimento de la ciudat por quanto se perdían muchas cosas del dicho spital por malos ministros en tiempos passados. ${ }^{31}$

Ítem, por a las cosas necessarias a dado la ciudat dos advocados y dos procuradores para que tengan solicitud en los pleitos y demandas que de contínuo fallen en los bienes del dicho spital a los quales dan sus pensiones.

La forma de recebir los enfermos

Ítem, es ordenado que quando algún enfermo a de venir al dicho spital, vienen los que lo tienen en casa y fablan con el regidor o substituydo [imne?] por aquel enfermo y el dicho manda al visitador lo vaya a veher y de que lo ha visto torna y faze relación al dicho regidor de la enfermedat que tiene y las horas enviará por enfermo con hun mulet el qual no tiene officio sino plegar la plega por la ciudat y traer los enfermos.

Ítem, es ordenado quel enfermo no pueda ser recebido en la enfermería sino que primero sia confessado y conbregado en la iglesia o spitalet que está a la entrada de casa en do hay dos camenyas, una por a los hombres otra por a las muyeres.

Ítem, en este spitalet les scrive el vicario todo lo que trahen fasta una agura y ge les conservar los enfermeros fasta que se levantan de la enfermedat y como reciben la dicha ropa por scripto por lo dicho así los dichos enfermeros la vuelven por el dicho memorial y si res se pierde la pagan los enfermeros.

Ítem, ante que dentra el dicho enfermo en la enfermería, lo squilan e limpian por tenerlos limpios en los lechos, lo qual es gran utilidat et lo tomarán los enfermeros y lo echan en su cama et luego vienen los meges y visítalo y segunt la enfermedat así le ordenan y lo que es de los hombres así mesmo es de las mulleres.

Ítem, pora el servicio de los dichos enfermos hay ocho enfermeros sirven a los dichos enfermos, los quales son ordenados de dos en dos, así la noche como el día tienen su guarda porque éstos may fallen de la enfermería y en la guarda de estos está el enfermero mayor que mira en todo y le son encomendadas todas las ropas de las camas y de los dichos enfermeros, esto mesmo es de las mulleres y el mesmo orden//s.f.

Ítem, es ordenado que de contínuo se dizen dos misas a los dichos enfermos y enfermas por a los quales hay dedicados dos clérigos.

Ítem, así mesmo dos clérigos que tienen cargo de leer las pasiones a los que estando in articulo mortis y darles la extremaunción, absolución plenaria e confirmarlos en la fe e decirles otras devociones devotas.

31 En tiempos passados: Esta expresión induce a pensar que estas ordenanzas son posteriores a las otorgadas en 1425 . 
Ítem, es ordenado que qualquier manera de criaturas se echen a la puerta del dicho hospital de noche se reciben y se conservan en una cámara llamada de las criaturas, en la qual cámara hay quatro nodricas de contínuo con leche para las criaturas que van y vienen con una madre que mira sobre todas y de aquí se dan a criar a nodriças fuera y se da de salario X sueldos por mes y el regidor de la casa tiene el Libro de las dichas nodricas el qual da conto y razón de las dichas criaturas.

Ítem, es ordenado por los sobredichos que las nodricas de las dichas criaturas les pagan sus salarios de seys en seys meses las quales vienen todas con las criaturas por dineros por a el qual pagament vienen los jurados con los otros regidores a la puerta de dicho spital y a cada una le tienen su conto e le pagan su [...] corrido, el munto de las quales criatures son según por el libro de dicho spital de present se demuestra de leche entera que se pagan a X sueldos e LXV e de media leche LXXIIII. Et es muy grande mérito que las más dellas se perderían sino por tal cosa como aquella.

Ítem, es ordenado que quando algún inocente se a de recebir en el dicho spital se recibe con voluntat de todos los dichos regidores e no en otra manera, los quales tienen su custodia e assí mismo las muxeres.

Ítem, es ordenado quel pan, vino y carne que en el dicho spital entre por a la provisión de la companya entra a conto la qual vitualla se encomienda al mayordomo y por este mayordomo al repostero y tienen conto de quantas personas comen cadaún día en la casa y por menudo se da toda la provisión que es menester y ellos dan conto qué carne, qué pan, qué vino se despiende en cada una jornada. Et así mismo el pan que se llega por el mulet quanto trahen y a peso se recibe y se sabe quanto pan viene de la dicha plega.

En la casa se despiende en cada anyo CCCC cafizes de trigo.

Ítem CCC [metros?] de vino [suisse?] malluelo.

Ítem, DCCC carneros.

Ítem $\mathrm{III}^{\mathrm{m}}$ gallinas.

Ítem, los comedores de contínuo son hun tiempo con otro CC personas a la contínua entre enfermos, inocentes, criaturas e servidores.

\section{Referencias Bibliográficas}

BAQUERO, A. (1952). Bosquejo histórico del hospital real y general de Nuestra Señora de Gracia de Zaragoza, Zaragoza, Institución Fernando el Católico.

CASTEJÓN, N. (2007): Aproximació a l'estudi de l'hospital de la Santa Creu de Barcelona. Barcelona, Fundació Noguera.

CONEJO, A. (2014): «Llum, noblesa, ornament, laor, glòria e amplitud: Los hospitales y la renovada imagen de la ciudad bajomedieval» en T. Huguet y otros, eds., Ciudad y hospital en el Occidente europeo, 1300-1700, Lleida, Milenio, 415-445. DANON, J. (1978): Visió histórica de l'hospital general de Santa Creu de Barcelona. Barcelona, Rafael Dalmau. 
GALLENT, M. (1980): La asistencia sanitaria en Valencia (1400-1512), tesis doctoral en microficha, 2 vols., Universitat de València.

- (1982): «El proceso de unificación de los hospitales valencianos (1482-1512)» en Estudios dedicados al Dr. Peset Aleixandre, vol. 2, 60-64.

- (1984): «Instituciones hospitalarias y poderes públicos en Valencia» en Saitabi, $34,75-88$.

- (2012): «El proceso de unificación hospitalaria. El Hospital General», en Hospital General de València (1512-2012), 2 vols., Valencia, vol. 1, 106-123.

- (en prensa): Orígenes del sistema sanitario valenciano. Documentos fundacionales del Hospital General de Valencia, Valencia, Institució Alfons el Magnànim.

GARCÍA, A. y otros (1990): Guía del Archivo de la Excma. Diputación Provincial de Valencia, Valencia, Generalitat Valenciana.

HENDERSON, J. (2006): The renaissance hospital: healing the body and healing the soul. New Haven, Yale University Press.

— , HORDEN P., PASTORE, A., eds. (2007): The impact of hospitals: 300-2000, Bern, Peter Lang.

HUGUET, T. y otros, eds. (2014): Ciudad y hospital en el occidente europeo, 13001700, Lleida, Milenio.

JÁVEGA, E. (2010): Expósitos en la Valencia de la primera mitad del siglo XVI, Valencia, Institució Alfons el Magnànim.

LÓPEZ, M. L. (2012): «Una institución asistencial renacentista: el Hospital General de Valencia durante el siglo XVI» en Hospital General de València (1512-2012), Valencia, vol. 1, 124-141.

MOLLAT, M. (1982): «Hospitalité, hopitaux et medicine» en L'emergenza storica delle attività terziarie (secc. XII-XVIII), $14^{\text {a }}$ Settimana di Studi Prato, actas no publicadas, ejemplar mecanografiado, 28 págs.

MONTERDE, C. (2008): «Las ordinaciones del hospital de Santa María de Gracia de Zaragoza establecidas por don Alfonso de Aragón, arzobispo de Zaragoza y lugarteniente general del reino» en Aragón en la Edad Media, 20, 505-528.

NAVARRO, G. (2000): «El hospital de Santa María de Villaespesa y de San Juan Bautista en la ciudad de Teruel a través de los actos notariales de Alfonso Jiménez (1481-1518)» en Aragón en la Edad Media, 16, 565-590.

ROCA, J. M. (1914): «La Medicina catalana en temps del rei Martí» en Butlletí del Centre Excursionista de Catalunya, Barcelona, 57-59.

- (1920): Ordinacions del Hospital General de la Santa Creu de Barcelona. Barcelona, Associació General de Metges de Llengua Catalana.

RODRIGO, J. (1922): Historia de la antigua y real Cofradía de Nuestra Señora de los Inocentes Mártires y Desamparados de la veneranda imagen y de su capilla. Valencia, Imprenta Hijo de F. Vives Mora.

VILLAGRASA, R. (2014): La red de hospitales en el Aragón medieval (ss. XII-XV), trabajo final del Máster Universitario en Investigación y Estudios Avanzados en Historia, Facultad de Filosofía y Letras, Universidad de Zaragoza. 